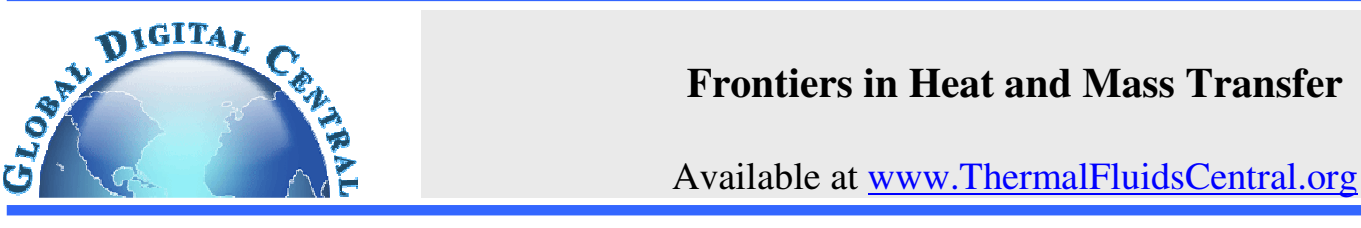

\title{
HEAT TRANSFER ENHANCEMENT OF HEAT EXCHANGER INSERTED TWISTED PLATES FOR CARBON DIOXIDE GAS
}

\author{
Makoto Shibahara* \\ Graduate School of Maritime Sciences, Kobe University, Kobe, 658-0022, Japan
}

\begin{abstract}
Overall heat transfer coefficients of the heat exchanger inserted twisted plates for $\mathrm{CO}_{2}$ were measured. The overall heat transfer coefficients increased with mass flow rates of water at the same Reynolds number in the experiment. It is considered that the helically twisting fluid motions in the twisted heat exchanger were contributed to the heat transfer enhancements.

Keywords: Heat transfer enhancement, Heat Exchanger, Twisted Plates
\end{abstract}

\section{INTRODUCTION}

It is important to reduce greenhouse gases in atmosphere for a control of global warming. In order to decrease the concentration of carbon dioxide gas $\left(\mathrm{CO}_{2}\right)$ in the atmosphere, the renewable energy technologies have been developed such as the biological gasification with biomass fuel and the direct combustion. Recently, the isolation technology of the emitted $\mathrm{CO}_{2}$ from the atmosphere is also considered to be effective. Liu et al. (2006) experimentally studied a solution process of $\mathrm{CO}_{2}$ in seawater and pure water under various pressures and temperatures. On the other hand, Willcox et al. (1982) proposed the concept of a marine biomass plantation (ocean farm) to create biomass fuel such as a kelp, then they gave the economic analyses three decades ago. Based on the concept of the ocean farm, Shibahara et al. (2008) have suggested on the marine renewable energy power plant combined the ocean farms. Figure 1 shows the basic concept of marine renewable energy power plant system. This system consists of micro gas turbine, heat exchangers, pumps, cooling water, liquid oxygen, and vessel for alkali solution such as amine adsorption. When the kelp is used as the marine biomass fuel with the high concentration of oxygen in the combustion chamber, the exhaust gas is composed of carbon dioxide gas and water as shown in following chemical equation.

$$
\mathrm{C}+2 \mathrm{H}_{2}+2 \mathrm{O}_{2} \rightarrow \mathrm{CO}_{2}+2 \mathrm{H}_{2} \mathrm{O}
$$

Then, $\mathrm{CO}_{2}$ captured by the alkali solution ships to the ocean farm. After distilling the adsorption solution with boilers, $\mathrm{CO}_{2}$ is disposed into the ocean farm by the pipeline and promotes growth of kelp (Zou, 2005). In this system, high-efficiency compact heat exchanger becomes necessary for the limit of the marine plant space, therefore, it is important to investigate the heat transfer enhancement of the heat exchanger through $\mathrm{CO}_{2}$ for the proposed power plant system.

Shibahara et al. $(2008,2009)$ have already reported about a transient heat transfer process for $\mathrm{CO}_{2}$ flowing over a horizontal plate under wide experimental conditions assuming the plate-type heat exchanger. Transient heat transfer coefficients for $\mathrm{CO}_{2}$ were measured to construct the fundamental database for the proposed power plant system. Moreover, the heat transfer coefficients for various gases flowing over a twisted plate were measured and obtained the empirical correlations in order to improve the heat transfer performance (Shibahara et al., 2010; Shibahara et al., 2013). As a result of experiment, the heat transfer coefficients of the twisted plate were 13 28\% higher than that of the plate one

The purpose of this study is to apply the heat transfer enhancement of twisted plates to a heat exchanger and to obtain the fundamental data of the heat exchanger for $\mathrm{CO}_{2}$. In the experiment, the overall heat transfer coefficients of twisted heat exchanger were measured.

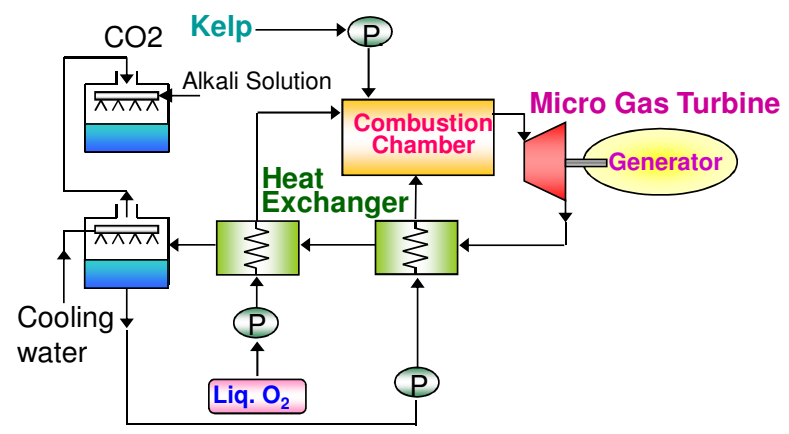

Fig.1 Schematic diagram of the marine renewable energy plant system (Shibahara et al. (2008)).

\section{EXPERIMENTAL APPARATUS}

Figure 2 shows the schematic diagram of the experimental apparatus. The experiment apparatus consists of a gas cylinder, mass flow meter, test section, flexible ribbon heater, isothermal bath, thermocouples and the data logger. The vacuum pump (ULVAC, DA-60D) was used to degas the tube. Flowing rate was measured with the mass flow meter (Azbil, CMS0050). And also, the pressure was measured with the pressure transducer (KEYENCE, AP-53A). The gas temperature in the

\footnotetext{
*E mail: sibahara@maritime.kobe-u.ac.jp
} 
tube was heated to the desired temperature level by a flexible ribbon heater. The temperature near test section heater was measured by $\mathrm{K}$ type thermocouples with a precision of $\pm 1 \mathrm{~K}$. $\mathrm{CO}_{2}$ with a high purity of $99.9 \%$ was used as the test fluid.

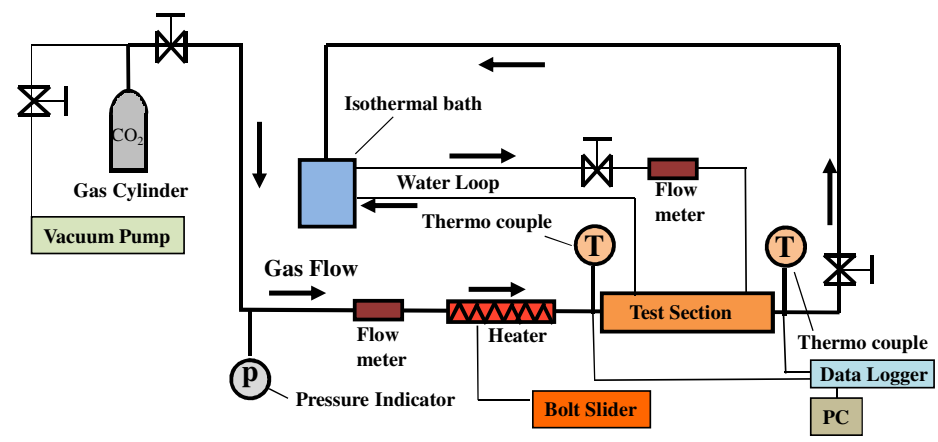

Fig.2 Schematic diagram of the experimental apparatus

Figure 3 shows the overview of the twisted heat exchanger. It consisted of a copper tube $(\phi 8 \times 150)$, twisted copper plates $(10 \times 150$ $\times 0.3)$ in parallel copper plates $(30 \times 130 \times 0.3)$. The swirl fluid motion was generated by the twisted plates outside the copper tube. Moreover, the twisted plate was also inserted in the copper tube to enhance heat transfer of $\mathrm{CO}_{2}$. Figure 4 shows the detail of the heat exchanger. The width of the inserted plate was $8 \mathrm{~mm}$ with the thickness of $0.3 \mathrm{~mm}$ and the pitch of the tape was $50 \mathrm{~mm}$ in the copper tube. The twist ratio is defined by the following equation (Fujita and Lopez, 1995).

$$
\gamma=\frac{H}{W}
$$

where, $H[\mathrm{~m}]$ and $W[\mathrm{~m}]$ are 180 degree twist-pitch of the twisted plate and width of the twisted plate. The twisted ratio was 9.0 in the copper tube. On the other hand, since the pitch of the external twisted plates was $130 \mathrm{~mm}$ as shown in Fig.4, the twisted ratio was 13.0.

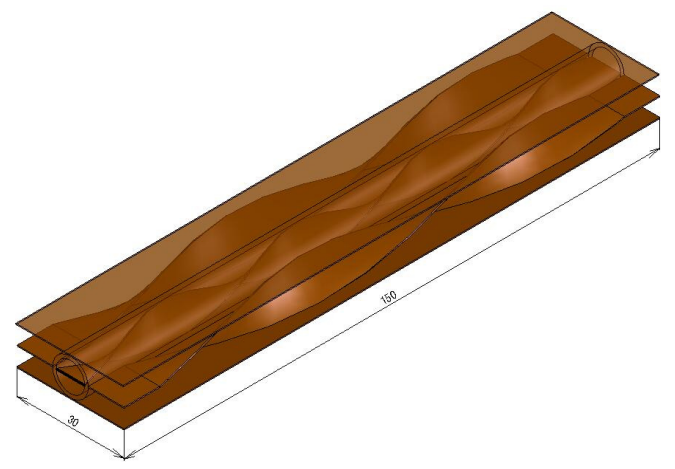

Fig.3 Overview of the twisted heat exchanger
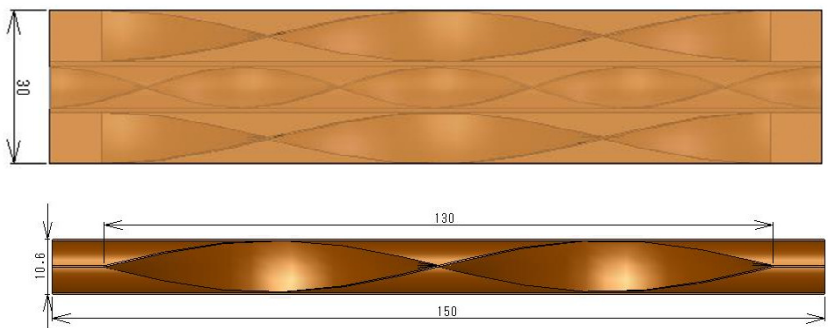

Fig.4 The detail of the twisted heat exchanger

\subsection{Experimental Method}

The mass flow rate was controlled using the regulator of gas cylinder at the experiment, and the gas temperature was heated through the flexible ribbon heater with a bolt slider. The gas temperatures were measured by the thermocouples connected to the data logger (KEYENCE GR3500). The gas flow velocity was ranged from $2.5 \mathrm{~m} / \mathrm{s}$ to $7.2 \mathrm{~m} / \mathrm{s}$. The heat transfer performance of the twisted heat exchanger was evaluated by means of a wind-tunnel experiment and water test in an acryl tube with the inner diameter of $46 \mathrm{~mm}$ and the length of $190 \mathrm{~mm}$ as shown in Fig.5. The countercurrent flow was ranged from $2.0 \mathrm{~m} / \mathrm{s}$ to $4.0 \mathrm{~m} / \mathrm{s}$ measured by hot-wire flow meter (Testo435) in the wind-tunnel experiment. On the other hand, the mass flow rate of the countercurrent flow was ranged from 0 to $6.7 \mathrm{~g} / \mathrm{s}$ in the water test.

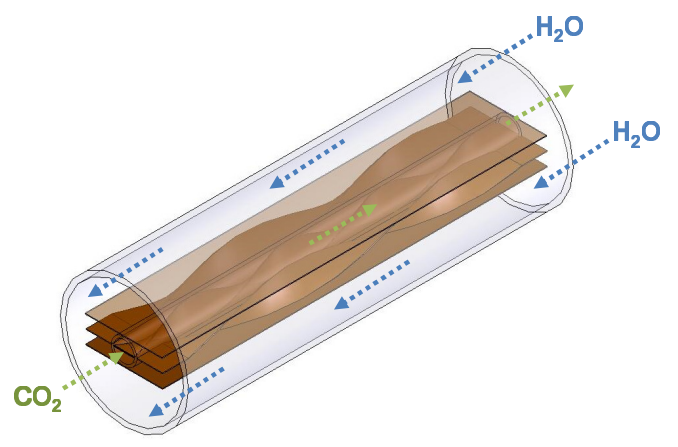

Fig.5 Water test of the heat exchanger

After these experiments, the heat transfer rate was calculated by the following equations as the data reduction.

$$
Q=V \rho c_{p}\left(T_{\text {in }}-T_{\text {out }}\right)
$$

where, $V\left[\mathrm{~m}^{3} / \mathrm{s}\right], \rho\left[\mathrm{kg} / \mathrm{m}^{3}\right], C_{p}[\mathrm{~J} / \mathrm{kg} \mathrm{K}], T_{\text {in }}[\mathrm{K}], T_{\text {out }}[\mathrm{K}]$ were volume of $\mathrm{CO}_{2}$, density of $\mathrm{CO}_{2}$, specific heat of $\mathrm{CO}_{2}$, inlet gas temperature and outlet gas temperature, respectively. And also, overall heat transfer coefficient was defined as follow:

$$
U=\frac{Q}{A \Delta T_{\text {in }}}
$$

where, $A\left[\mathrm{~m}^{2}\right]$ was estimated as the area of inner diameter of the copper tube since the inserted tape was lose fit in the copper tube. $\Delta T_{\text {in }}[\mathrm{K}]$ was log mean temperature difference. On the other hand, the Reynolds number was defined as follows:

$$
R e_{h}=\frac{u D_{h}}{v}
$$

where, $u[\mathrm{~m} / \mathrm{s}], v\left[\mathrm{~m}^{2} / \mathrm{s}\right], D_{h}[\mathrm{~m}]$ were the flow velocity, kinematic viscosity and hydraulic diameter, respectively. Since the twisted plate was inserted in the tube, the hydraulic diameter (Fujita and Lopez, 1995) can be expressed as

$$
D_{h}=D \frac{1-(4 \delta / \pi D)}{1+(2 / \pi)(1-\delta / D)}
$$

where, $D[\mathrm{~m}]$ and $\delta[\mathrm{m}]$ were the inner diameter and thickness of plate, respectively.

\subsection{Experimental Result}

Figure 6 shows the time-dependence of the inlet gas temperature and outlet gas temperature under the gas pressure of $104.8 \mathrm{kPa}$. The gas 
flow velocity was $2.5 \mathrm{~m} / \mathrm{s}$ and the countercurrent flow of air was 2.0 $\mathrm{m} / \mathrm{s}$. As shown in Fig.6, a rise of the inlet gas temperature was observed after turning on the flexible ribbon heater. The outlet gas temperature also ascends gradually depending on the increase of the inlet gas temperature. Since these gas temperature approaches to asymptotic value after $400 \mathrm{~s}$, it is understood that the heat transfer process becomes steady-state condition.

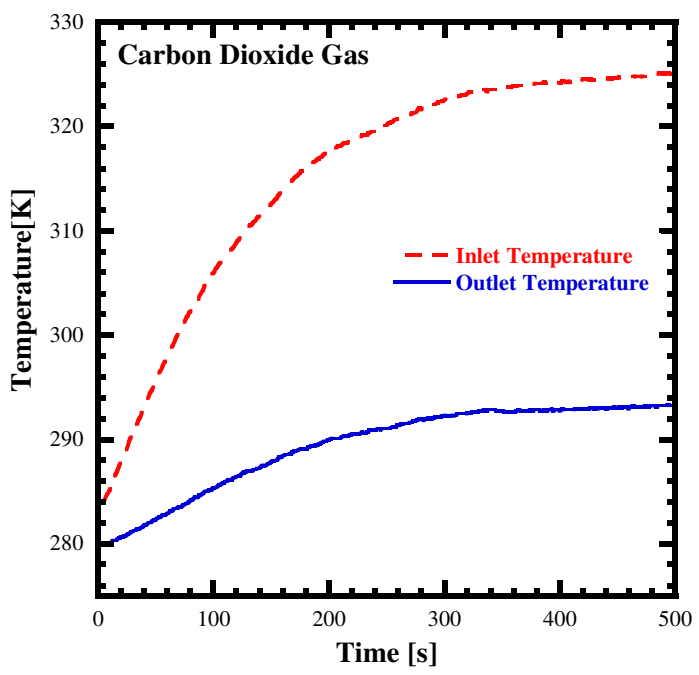

Fig.6 The time-dependence of the inlet and outlet temperature.

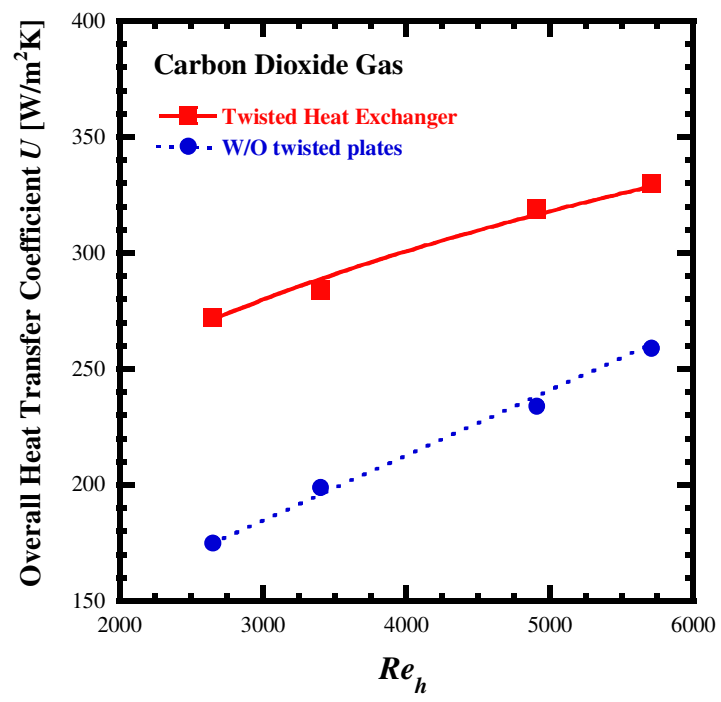

Fig.7 The relation of the overall heat transfer coefficients and Reynolds number at the countercurrent flow of $3 \mathrm{~m} / \mathrm{s}$ in air.

Figure 7 shows the overall heat transfer coefficient for the inlet gas temperature of $323.15 \mathrm{~K}$ at the various Reynolds number. The countercurrent flow of air was $3.0 \mathrm{~m} / \mathrm{s}$ in the acryl tube. Since the overall heat transfer coefficient increased with Reynolds number, it is considered that convective heat transfer comes to govern in the acryl tube. For comparison, the experimental result of a heat exchanger without twisted plates was plotted in Fig.7. The overall heat transfer coefficients of the twisted heat exchanger were higher than that of a heat exchanger without the twisted plates. It is understood that they were also affected by the Reynolds number as well as usual convective heat transfer.

Figure 8 shows the relation of the overall heat transfer coefficients and Reynolds number at the various countercurrent flows in water. The inlet gas temperature was $323.15 \mathrm{~K}$. The overall heat transfer coefficients increased with mass flow rates of water at the same Reynolds number. Comparing with the experimental result of the heat exchanger without the twisted plates, the overall heat transfer coefficients of the twisted heat exchanger were higher than that without the twisted plates at the mass flow rate of $1.7 \mathrm{~g} / \mathrm{s}$. It is considered that the swirl effect of the twisted plates contributed to the heat transfer enhancements. Thus, the fluid structure changed to the swirl flow caused by the twisted plate. In addition, the heat transfer enhancement in the each copper tube was contributed by the twisted tape. It was considered that the flow velocity near the twisted tape in the each copper tube increased due to the blockage of the flow path as well as a single tube inserted a twisted tape (Manglik and Bergles, 1993).

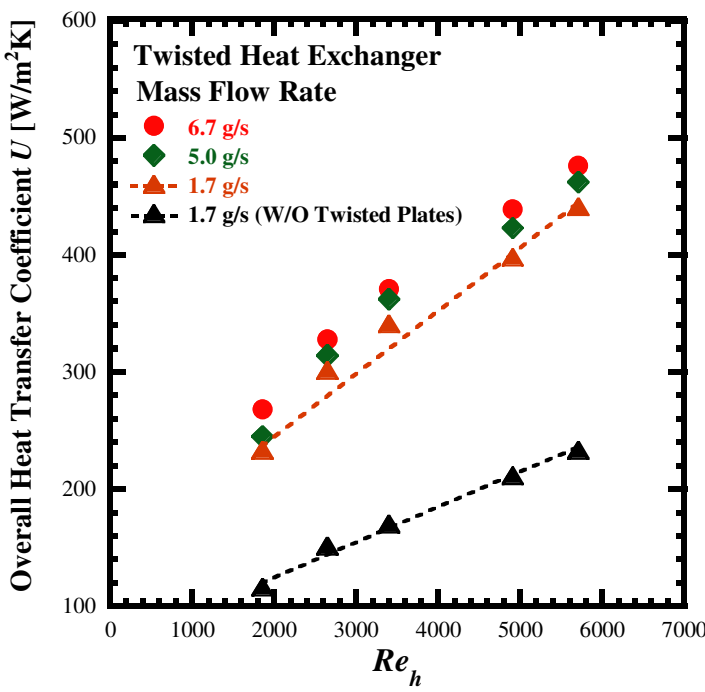

Fig.8 The overall heat transfer coefficients at various Reynolds number in water.

\section{CONCLUSION}

The heat transfer performance of the twisted heat exchanger was investigated experimentally. The overall heat transfer coefficients increased with mass flow rates of water at the same Reynolds number in the experiment. It is considered that the helically twisting fluid motions in the twisted heat exchanger were contributed to the heat transfer enhancements.

\section{NOMENCLATURE}

A area of inner diameter, $\mathrm{m}^{2}$

$c_{p} \quad$ specific heat of $\mathrm{CO}_{2}, \mathrm{~J} /(\mathrm{KgK})$

$D$ inner diameter, $\mathrm{m}$

$D_{h} \quad$ hydraulic diameter, $\mathrm{m}$

$H \quad 180$ degree twist-pitch

$Q$ heat transfer rate, $\mathrm{W}$

Re Reynolds number, $u D_{h} / v$

$T$ temperature, $\mathrm{K}$

$\Delta T \quad \log$ mean temperature difference, $\mathrm{K}$

$U$ overall heat transfer coefficient, $\mathrm{W} / \mathrm{m}^{2} \mathrm{~K}$

$V \quad$ volume flow of $\mathrm{CO}_{2}, \mathrm{~m}^{3} / \mathrm{s}$

$W \quad$ width of twisted plate, $\mathrm{m}$

$u$ gas flow velocity, $\mathrm{m} / \mathrm{s}$

$\delta$ plate thickness, $\mathrm{m}$

$\gamma \quad$ twist ratio

$\rho$ density of $\mathrm{CO}_{2}, \mathrm{~kg} / \mathrm{m}^{3}$

$v \quad$ kinematic viscosity, $\mathrm{m}^{2} / \mathrm{s}$

Subscripts

in inlet

out outlet

h hydraulic diameter 


\section{ACKNOWLEDGMENTS}

This work was partially supported by JSPS KAKENHI Grant Number 26820381.

\section{REFERENCES}

CFD2000, 2005, "Theoretical Background," Adaptive research. Howard, A.W, 1982, "The Ocean as a Supplier of Food and Energy", Cellular and Molecular Life Sciences, 38(1), 31-35. http://dx.doi.org/10.1007/BF01944522

Shibahara, M., Liu, Q., Fukuda, K., 2008, "Heat Transfer Performance of Plate Heater for Carbon Dioxide Gas in a Dispersed Power Plant System Using Marine Biomass Resource," 3rd Pan Asian Association of Maritime Engineering Societies and Advanced Maritime Engineering Conference, 863-869.

Shibahara, M., Liu, Q., Fukuda, K., "Transient Forced Convection Heat Transfer for Carbon Dioxide Flowing over a Horizontal Plate with Exponentially Increasing Heat Input," IMECE2008-68603, Proceedings of 2008 ASME International Mechanical Engineering Congress and Exposition, Boston, MA. http://dx.doi.org/10.1115/IMECE2008-68603

Shibahara, M., Liu, Q., Fukuda, K., 2009, “Transient Forced Convection Heat Transfer Due to Exponentially Increasing Heat Input for Helium Gas Flowing on a Narrow Plate," Journal of Power and Energy Systems, 3(1), 272-288.

http://dx.doi.org/10.1299/jpes.3.272 of the Japan Institute of Marine Engineering, 45, 99-101. http://dx.doi.org/10.5988/jime.45.1033

Shibahara, M., Liu, Q., Fukuda, K., 2013, "Enhancement of Forced Convection Heat Transfer Using Twisted Heater with Exponential Heat Inputs," HT2013-17227, Proceedings of ASME 2013 Summer Heat Transfer Conference, Minneapolis, MN. http://dx.doi.org/10.1115/HT2013-17227

Manglik, R.M., Bergles, A.E., 1993, "Heat Transfer and Pressure Drop Correlations for Twisted - Tape Inserts in Isothermal Tubes: Part I Laminar Flows," Journal of Heat Transfer, 115(4), 881-889. http://dx.doi.org/10.1115/1.2911383

Manglik, R.M., Bergles, A.E., 1993, "Heat Transfer and Pressure Drop Correlations for Twisted - Tape Inserts in Isothermal Tubes: Part II Transition and Turbulent Flows," Journal of Heat Transfer, 115(4), 890-896. http://dx.doi.org/10.1115/1.2911384

Liu, Q., Fukuda, K., Matsuda, T., 2006, "Study of Solution Process of Carbon Dioxide in Sea Water", Journal of the Japan Institution of Marine Engineering (Special Issue), 41, 144-149.

http://dx.doi.org/10.5988/jime.41.SI_144

Fujita, Y., and Lopez, A.M., 1995, "Heat Transfer Enhancement of Twisted Tape Inserts in Turbulent Pipe Flows," Transactions of JSME Series B, 61(588), 280-287. http://dx.doi.org/10.1299/kikaib.61.3044

Zou, D., 2005, "Effects of Elevated Atmospheric $\mathrm{CO}_{2}$ on Growth, Photosynthesis and Nitrogen Metabolism in the Economic Brown Seaweed, Hizikia, Fusiforme (Sargassaceae, Phaeophyta), Aquaculture, 250, 726-735.

http://dx.doi.org/10.1016/j.aquaculture.2005.05.014
Shibahara, M., Liu, Q., Fukuda, K., 2010, "Enhanced Transient Heat Transfer Caused by Partially Twisted Heater in Various Gases", Journal 